DOI 10.1007/s00417-003-0821-7

Kaan Gündüz

Carol L. Shields

Ilhan Günalp

Esra Erden

Jerry A. Shields

\section{Orbital schwannoma: correlation of magnetic resonance imaging and pathologic findings}

Published online: 10 February 2004

(C) Springer-Verlag 2004

The online version of the original article can be found at http://dx.doi.org/10.1007/ s00417-003-0681-1

\section{K. Gündüz (ब)}

G.M.K. Bulvar1 116/3,

06570 Maltepe, Turkey

e-mail: eyemd@ada.net.tr

Fax: +90-312-2291812

K. Gündüz · I. Günalp

Oncology Service,

Department of Ophthalmology,

Ankara University Faculty of Medicine,

Ankara, Turkey

C. L. Shields $\cdot$ J. A. Shields

Oncology Service, Wills Eye Hospital,

Thomas Jefferson University,

Philadelphia, Pennsylvania, USA

E. Erden

Department of Pathology,

Ankara University Faculty of Medicine,

Ankara, Turkey

\section{Graefe's Arch Clin Exp Ophthalmol (2003)}

\section{1:593-597}

Materials and Methods section, 2nd paragraph, 1th line:

The first sentence should read "After preoperative MRI was obtained, the patients underwent orbitotomy for tumor removal" instead of "After preoperative MRI was obtained, the patients underwent orbitotomy and the tumors were totally excised." 